\title{
ON STEVIĆ-SHARMA OPERATOR FROM THE MIXED-NORM SPACES TO ZYGMUND-TYPE SPACES
}

\author{
Zhitao GUO*, Linlin LiU AND Yonglu Shu
}

Abstract. Let $\varphi$ be an analytic self-map of the unit disk $\mathbb{D}, \mathscr{H}(\mathbb{D})$ the space of all analytic functions on $\mathbb{D}$, and $\psi_{1}, \psi_{2} \in \mathscr{H}(\mathbb{D})$. The boundedness and compactness of Stević-Sharma operator $T_{\psi_{1}, \psi_{2}, \varphi} f=\psi_{1} \cdot f \circ \varphi+\psi_{2} \cdot f^{\prime} \circ \varphi$ from the mixed-norm space $H(p, q, \phi)$ to Zygmund-type space $\mathscr{Z}^{\mu}$ and little Zygmund-type space $\mathscr{Z}_{0}^{\mu}$ are investigated in this paper.

Mathematics subject classification (2010): Primary 47B38; Secondary 47B33, 46B50, 46E15.

Keywords and phrases: Stević-Sharma operator, boundedness, compactness, mixed-norm spaces, Zygmund-type spaces.

\section{REFERENCES}

[1] M. S. Al Ghafri And J. S. Manhas, On Stević-Sharma operators from weighted Bergman spaces to weighted-type spaces, Math. Inequal. Appl. 23, 3 (2020), 1051-1077.

[2] C. C. Cowen AND B. D. MACCluer, Composition operators on spaces of analytic functions, Studies in Advanced Mathematics. CRC Press, Boca Raton, 1995.

[3] J. GuO AND Y. LiU, Generalized integration operators from mixed-norm to Zygmund-type spaces, Bull. Malays. Math. Sci. Soc. 39, 3 (2016), 1043-1057.

[4] Z. Guo AND Y. SHu, On Stević-Sharma operators from Hardy spaces to Stević weighted spaces, Math. Inequal. Appl. 23, 1 (2020), 217-229.

[5] Z. JIANG, On Stevic-Sharma operator from the Zygmund space to the Bloch-Orlicz space, Adv. Differ. Equ. 2015, 228 (2015), 12pp.

[6] H. Li AND Z. GuO, Note on a Li-Stević integral-type operator from mixed-norm spaces to $n$th weighted spaces, J. Math. Inequal. 11, 1 (2017), 77-85.

[7] S. Li And S. STEVIĆ, Volterra-type operators on Zygmund spaces, J. Inequal. Appl. 2007, Art. ID 32124 (2007), $10 \mathrm{pp}$.

[8] S. Li AND S. STEVIĆ, Generalized composition operators on Zygmund spaces and Bloch type spaces, J. Math. Anal. Appl. 338, 2 (2008), 1282-1295.

[9] S. Li AND S. STEVIĆ, Riemann-Stieltjes operators between mixed norm spaces, Indian J. Math. 50, 1 (2008), 177-188.

[10] S. LI AND S. STEVIĆ, Products of composition and differentiation operators from Zygmund spaces to Bloch spaces and Bers spaces, Appl. Math. Comput. 217, 7 (2010), 3144-3154.

[11] Y. LiU, X. LIU AND Y. YU, On an extension of Stevic-Sharma operator from the mixed-norm space to weighted-type spaces, Complex Var. Elliptic Equ. 62, 5 (2017), 670-694.

[12] Y. LiU AND Y. YU, Weighted differentiation composition operators from mixed-norm to Zygmund spaces, Numer. Funct. Anal. Optim. 31, 7-9 (2010), 936-954.

[13] Y. LiU AND Y. YU, The multiplication operator from mixed-norm to $n$-th weighted-type spaces on the unit disk, Math. Inequal. Appl. 15, 2 (2012), 437-448.

[14] Y. LiU AND Y. YU, On Stević-Sharma type operator from the Besov spaces into the weighted-type space $H_{\mu}^{\infty}$, Math. Inequal. Appl. 22, 3 (2019), 1037-1053.

[15] Y. LiU AND J. ZHOU, On an operator $M_{u} R$ from mixed norm spaces to Zygmund-type spaces on the unit ball, Complex Anal. Oper. Theory 7, 3 (2013), 593-606. 
[16] K. Madigan And A. Matheson, Compact composition operators on the Bloch space, Trans. Amer. Math. Soc. 347, 7 (1995), 2679-2687.

[17] A. K. Sharma, Products of composition multiplication and differentiation between Bergman and Bloch type spaces, Turk. J. Math. 35, 2 (2011), 275-291.

[18] A. Shields AND D. Williams, Bounded projections, duality, and multipliers in spaces of analytic functions, Trans. Amer. Math. Soc. 162, (1971), 287-302.

[19] S. STEVIĆ, Boundedness and compactness of an integral operator in a mixed norm space on the polydisk, Siberian Math. J. 48, 3 (2007), 559-569.

[20] S. STEVIĆ, Generalized composition operators between mixed-norm and some weighted spaces, Numer. Funct. Anal. Optim. 29, 7-8 (2008), 959-978.

[21] S. STEVIĆ, Generalized composition operators from logarithmic Bloch spaces to mixed-norm spaces, Util. Math. 77, (2008), 167-172.

[22] S. STEVIĆ, Boundedness and compactness of an integral operator between $H^{\infty}$ and a mixed norm space on the polydisk, Siberian Math. J. 50, 3 (2009), 495-497.

[23] S. STEvić, Composition operators from the weighted Bergman space to the nth weighted spaces on the unit disc, Discrete Dyn. Nat. Soc. Art. 2009, Art. ID 742019, (2009), 11 pp.

[24] S. STEvić, On an integral-type operator from logarithmic Bloch-type and mixed-norm spaces to Bloch-type spaces, Nonlinear Anal. 71, 12 (2009), 6323-6342.

[25] S. STEVIĆ, Weighted differentiation composition operators from mixed-norm spaces to weighted-type spaces, Appl. Math. Comput. 211, 1 (2009), 222-233.

[26] S. STEvić, Composition operators from the Hardy space to the $n$th weighted-type space on the unit disk and the half-plane, Appl. Math. Comput 215, 11 (2010), 3950-3955.

[27] S. STEvić, Composition followed by differentiation from $H^{\infty}$ and the Bloch space to nth weightedtype spaces on the unit disk, Appl. Math. Comput. 216, 12 (2010), 3450-3458.

[28] S. STEVIĆ, Extended Cesàro operators between mixed-norm spaces and Bloch-type spaces in the unit ball, Houston J. Math. 36, 3 (2010), 843-858.

[29] S. STEVIĆ, On an integral-type operator from Zygmund-type spaces to mixed-norm spaces on the unit ball, Abstr. Appl. Anal. 2010, Art. ID 198608 (2010), 7 pp.

[30] S. STEVIĆ, Weighted differentiation composition operators from the mixed-norm space to the nth weighted-type space on the unit disk, Abstr. Appl. Anal. 2010, Art. ID 246287, (2010), 15 pp.

[31] S. STEVIĆ, Weighted radial operator from the mixed-norm space to the $n$th weighted-type space on the unit ball, Appl. Math. Comput. 218, 18 (2012), 9241-9247.

[32] S. Stević And A. K. Sharma, Composition operators from weighted Bergman-Privalov spaces to Zygmund type spaces on the unit disk, Ann. Polon. Math. 105, 1 (2012), 77-86.

[33] S. STEVIĆ, A. K. Sharma AND A. Bhat, Essential norm of products of multiplication composition and differentiation operators on weighted Bergman spaces, Appl. Math. Comput. 218, 6 (2011), 23862397.

[34] S. Stević, A. K. Sharma And A. Bhat, Products of multiplication composition and differentiation operators on weighted Bergman space, Appl. Math. Comput. 217, 20 (2011), 8115-8125.

[35] S. Ye AND Q. Hu, Weighted composition operators on the Zygmund Spaces, Abstr. Appl. Anal. 2012, Art. ID 462482, (2012), 18 pp.

[36] Y. YU AND Y. LiU, On Stević type operator from $H^{\infty}$ space to the logarithmic Bloch spaces, Complex Anal. Oper. Theory 9, 8 (2015), 1759-1780.

[37] F. Zhang AND Y. LiU, On a Stević-Sharma operator from Hardy spaces to Zygmund-type spaces on the unit disk, Complex Anal. Oper. Theory 12, 1 (2018), 81-100. 